\title{
Study on Evaluation of Asset Quality in Enterprises Based on DEA Model
}

\author{
Xiaoying Chen \\ Department of Economics, Shan Dong Jiaotong University \\ Jinan 250357, Shandong, China \\ E-mail: sdjnxsy@163.com
}

Received: March 20, $2011 \quad$ Accepted: April 18, $2011 \quad$ doi:10.5430/ijba.v2n2p35

\begin{abstract}
The quantity of assets, especially the quality of assets, plays a crucial role in development of enterprises. For the time being, most studies about asset quality of enterprises are limited to qualitative analysis and there are rarely studies of quantitative evaluation. DEA analysis method is one which studies whether a multiple element input and multiple output system is relatively effective. We may regard an enterprise as a system with input of asset element and output of quality benefit. This article employed a quantitative method to discuss asset quality evaluation based on DEA Model by irrationally selecting asset element input indexes and quality benefit output indexes. Then, the author analyzed applicability and merits as well as disadvantages of this method.
\end{abstract}

Keywords: DEA Model, Asset quality, Effectiveness of scale, Effectiveness of technique

\section{Summary of studies on evaluation of asset quality}

Assets of an enterprise are the fundamental element for the enterprise to compete in the market. Assets are economic resources that have been generated in previous transactions or items and may bring economic profits for the enterprise within an anticipated period of time. The quantity and quality of assets might bring totally different influences upon the short-term operation and long-term development of the enterprise.

A general survey on studies of asset quality both at home and abroad, we find that most studies by domestic and foreign academics are focused upon relationship between asset quality and credit risk and scale economy and relationship between asset quality of enterprises and production efficiency, etc. For instance, Harris and Raviv (1990) applied debt alleviation model (also termed as HR Model) to make a research that quality of a company determined its capital structure and ultimately affected the value of the company. Bernstein (1996) conducted a study on asset quality and scale economy of the bank and through his study; he found out that the loan quality had direct or indirect influence on the cost of the bank. Academics at home have more studies on the characteristics of asset quality, most of which are qualitative studies. There are some typical studies as listed below: Gan Shengdao \& Wang Shengbin (2000) believed that asset quality was the overall reflection of asset profitability, liquidity and turnover of an enterprise; Zhang Xinmin (2009) held the view that asset quality referred to the quality an enterprise anticipates and expects in the process of the corporate management that is satisfied by specific assets, manifested in details as such quality characteristics as fluidity, individual increment, turnover and increment in combination with other assets. This kind of study is quite necessary. Just as we study the quality characteristics of accounting information, only if we firstly make clear the quality characteristics, can the target of enhancing the quality is proposed. There are also some other academics who employed empirical research, such as Li Jiaming \& Li Songmin (2005). In study of relevance between asset quality and enterprise performance, academics usually selected several financial indexes as the variables of asset quality which reflected the characteristics of asset quality. Variables of asset quality employed in these studies were often determined subjectively and usually didn't take into account all the asset input elements. In this article, the author is going to employ DEA Model to evaluate asset quality of an enterprise from the perspective of all asset input elements, and analyze and evaluate the optimal combination of asset element input and quality benefit output in the process of asset quality generation.

The object for which we evaluate the asset quality is an enterprise, which we term as evaluated enterprise. An evaluated enterprise can be seen as a system with multiple inputs and multiple outputs, which can also be called decision making unit. Formation of all sorts of assets of an enterprise is the outcome of input of all kinds of resources, which is considered the asset element input index. The quality benefit parameter is regarded as the output index. Accordingly, 
evaluation of asset quality can be further converted into the running efficiency of the system of enterprise in asset element input and quality benefit output. $\mathrm{C}^{2} \mathrm{R}$ Model is the most fundamental model in DEA, which is a method used to study that "production unit" with multiple inputs, and especially multiple outputs, has "effectiveness of scale" and also "effectiveness of technique". "Effectiveness of scale" means that the scale of input elements in the process of quality formation is effective. That is to say, with the precondition that features of the quality are generally accepted by users, usage of input elements realizes minimum consumption or the most economical consumption, namely, "effectiveness of scale". "Effectiveness of technique" means that the technique of input elements in the process of quality formation is effective. That is to say, under the technical conditions that input elements have at that time, the quality benefit is achieved the maximum level, namely, "effectiveness of technique". Yet, "effectiveness of scale" and "effectiveness of technique" is exactly our target to make evaluation on asset quality. In the light of this, this article is going to employ DEA method to make an overall and accurate evaluation on the quality of input elements of all assets of an enterprise. We regard an enterprise as an evaluated system with combination of asset element input and quality benefit output, employ DEA Model and select all asset element input indexes and quality benefit output indexes to discuss a quantitative analysis method about evaluation of asset quality so as to make up for disadvantages in the qualitative analysis of asset quality.

\section{Design of evaluation indexes}

\subsection{Influential factors for design of evaluation indexes}

In selection of an index, we should not only take into consideration the characteristics of evaluation per se, but should also make relationship between all indexes clear and intuitive. All indexes selected ought to fully reflect the overall situation of asset quality and acquire information there from as much as possible. Generally speaking, the following several factors ought to be taken into account in establishment of the system of indexes evaluating asset element input and quality benefit output.

(1) Indexes reflected by all input variables and output variables have to be comprehensive and be able to successfully realize our evaluation target;

(2) Since all input variables and output variables do not exist in isolation, we have to take into account certain link possibly existing among them and try to reduce interference in or influences on other index elements. Then, the evaluation and analysis process is of great objectivity;

(3) Usually, an index system is not uniquely determined and has its diversity, but an index system should reflect the essence of the evaluation. Then, the result of evaluation is of practical significance to our economic and living activities.

\subsection{Principles for design of evaluation indexes}

We have to follow the following three principles in establishing an index system, namely, scientific principle, comparability principle and feasibility principle. The scientific principle means that an index system has to reflect the entire and essential attributes of an object evaluated; the comparability principle means that the statistical specification and statistical scope should be consistent in the process of evaluation, so that the feature of inter-comparison may exist among different evaluated objects; the feasibility principle means that the data should have the property of being collected and the evaluation method should have the property of maneuverability so as to make the evaluation work successfully accomplished.

In designing the indexes of evaluation on asset quality, we should attempt to take an overall account into input of all sorts of asset elements, for different sorts of assets lead to different purposes of holding and play different roles in the production and operation of an enterprise, which other sorts of assets have no means to replace. Thus, this article selects six different asset input indexes, which almost cover types of all sorts of assets of the enterprises.

\subsection{Selection of evaluation indexes}

In designing the indexes of evaluation on asset quality, we should attempt to take an overall account into input of all sorts of asset elements, for different sorts of assets lead to different purposes of holding and play different roles in the production and operation of an enterprise, which other sorts of assets have no means to replace. Thus, this article selects six different asset input indexes, which almost cover types of all sorts of assets of the enterprises.

\subsubsection{Index of asset input}

\subsubsection{Monetary assets}

Monetary assets not only include realistic currency and the deposits of an enterprise in a bank, but also include all sorts of bills and securities that have realistic payment capacity, such as bond maturing within three months and transactional 
monetary capital. The purpose of an enterprise to hold monetary assets is usually to satisfy the transactional demand, prevention need, demand of the bank and speculative demand.

\subsubsection{Accounts receivables}

Enterprises may have such debt assets as accounts receivables, notes receivables, accounts prepaid and other accounts receivables as a result of selling products on credit, offering labor service or other reasons. In a common situation, any enterprise prefers to sell with cash, but not on credit selling. Yet, under the competitive pressure, credit selling and offering funds for clients that are needed to purchase commodities is an important measure that has to be taken by a large majority of enterprises to enhance the competitive competence and expand sale, namely, to make an investment in accounts receivables. Although credit selling is able to enhance the competitive competence of an enterprise and expand its sale, on the other hand, it might add to the direct cost and indirect cost of management of accounts receivables.

\subsubsection{Inventory}

Inventory refers to goods and materials an enterprise stores for sale or consumption in the process of production and operation. Inventory mainly includes material, fuel, goods in process, semi-finished products, finished goods, cooperative processing semi-finished products and commodities, etc. Functions of inventory exist within an enterprise and different departments have different demands on inventory control. For example, from the perspective of capital usage, the financial department wishes that the less inventory capital occupied, the better and intends to reduce inventory as much as possible. By contrast, from the perspective of ensuring production, the production department wishes to maintain high inventory level so as to avoid or reduce any delay in production.

\subsubsection{External speculative assets}

External speculative assets contain the financial assets available for sale, the financial assets held to maturity and long-term equity investment. The common characteristic of these three kinds of assets is that the enterprises intend to hold external speculative assets in the long run. Income on investment acquired from the financial assets available for sale and the financial assets held to maturity is relatively stable and has relatively low risk. However, purposes of long-term equity investment are various. Some long-term equity investment is aimed to establish and maintain a stable business relation with the enterprise invested and straighten out the upstream and downstream supply and marketing channel. There is also some long-term equity investment which is aimed to fulfill horizontal integration and enlarge market shares and competitive strength in the industry. Still, some other long-term equity investment is aimed at strengthening diversified operation capacity of the enterprise so as to enhance the ability of the enterprise to resist the risk or create new sources of profits.

\subsubsection{Permanent assets}

Permanent assets are an important labor means for an enterprise to operate and are the primary material foundation for an enterprise to gain profits. It plays a significant role in the process of production and operation of an enterprise. Permanent assets are helpful for an enterprise to enhance its labor productivity, improve the working conditions, enlarge scale of production and operation and diminish production cost.

\subsubsection{Intangible assets}

Intangible assets are taking the place of tangible assets and become the primary driving element for an enterprise to create its value. This reality has already had no space for dispute. The quantity and quality of intangible assets decides the short-term operation and long-term development of an enterprise and determines the rise and decline and success and failure of the enterprise. Nevertheless, intangible assets have no entity pattern, with great uncertainty in creating economic profits, and have to be combined with other assets sometimes to create value.

\subsubsection{Index of quality benefit}

In selecting parameter of quality benefit, we can weigh from the two perspectives of accrual accounting and cash system of accounting. That is to say, we can not only select the index of income and the index of profit, but can also select the index of cash flow. Furthermore, these three indexes are easy to obtain in a financial statement.

\subsubsection{Operating income}

Operating income refers to income created by an enterprise with all kinds of assets in the daily activity and is the achievement of an enterprise in employing its assets, which includes main business income and other business incomes. Income in the income statement is confirmed and calculated according to the accrual accounting principle, so there isn't substantial economic income flow in gaining some incomes. Therefore, we have to take into consideration the cash flow in the operation activities. 


\subsubsection{Core profit}

Core profit refers to the operational achievement by deducting expenses generated in the daily activities from the income created by an enterprise with all sorts of assets in the daily activities. Namely:

Core profit $=$ Operating income - Operating cost - Operating tariff and annex- Period expense

Core profit has got rid of gains and losses in some accidental incidents which occurred outside daily operation activities of the enterprises, since these gains and losses usually have nothing to do with profits generated in normal usage of the assets of the enterprises.

\subsubsection{Net profit after deducting extraordinary gain or loss}

Extraordinary gain or loss refers to those incomes and expenses in which a listed company has direct relationship with the production and operation or which although is related with the production and operation, yet affects an authentic and fair evaluation on the current operation achievement and earnings-generating capacity of the company as a result of its property, amount or frequency of occurrence. Extraordinary gain or loss belongs to a one-time or accidental acquisition, with low content of gold, and is unable to display the usage effectiveness of assets of the enterprises. Thus, we regard the net profit after deducting extraordinary gain or loss as a quality benefit index.

\subsubsection{Net cash flow in operation activities}

Index of net cash flow in operation activities reflects the operation achievement of an enterprise after offset of cash inflow and cash outflow in the daily operation activities from the perspective of cash system of accounting. This index is able to make up for disadvantages of such indexes as income and profit under the accrual accounting system.

\subsubsection{Net amount of cash flow}

Net amount of cash flow also reflects the operation achievement of an enterprise from the perspective of cash system of accounting, which not only takes into account the achievement of operation activities, but also takes into consideration investment activities and financial activities. Investment activities and financial activities are also closely interrelated with usage of the assets and are also a comprehensive reflection of usage benefit of the assets.

Summary sheet of the index system is shown in Table 1.

\section{Method of evaluation on the asset quality of an enterprise based on DEA Model}

Supposed that the number of enterprises which are evaluated is n. Each enterprise is marked as DMU and each DMU has $\mathrm{m}$ (here $\mathrm{m}=6$ ) kinds of input indexes (input of all sorts of asset elements) and $\mathrm{s}$ (here $\mathrm{s}=5$ ) kinds of output indexes (quality benefit parameter). We use $x_{n j}$ to represent the quantity of $D M U$; in input of the $\mathrm{m}^{\text {th }}$ asset, and use $y_{s j}$ to represent the quantity of $D M U_{j}$ in output of the $\mathrm{s}^{\text {th }}$ asset. Then, the input and output vector of all $D M U_{\text {; }}$ can be respectively expressed as: $x_{j}=\left(x_{1 j}, x_{2 j}, \cdots x_{m j}\right)^{T} y_{j}=\left(y_{1 j}, y_{2 j}, \cdots y_{s j}\right)^{T}(\mathrm{j}=1,2, \ldots, \mathrm{n})$.

Supposed that the weight vectors of the input and output indexes are respectively as below:

$V=\left(v_{1}, \mathcal{V}_{2}, \cdots v_{i}, \cdots v_{m}\right)^{T} U=\left(u_{1}, u_{2}, \cdots u_{i}, \cdots u_{s}\right)^{T}$. Then, the asset quality of $D M U$, can be expressed as below:

$$
E_{j}=\frac{U^{T} Y_{j}}{V^{T} X_{j}}
$$

Where, $U^{T}$ and $V^{T}$ respectively stand for the weight vector of input and output. When the weight $\mathrm{u}_{\mathrm{m} \text { and weight }} \mathrm{v}_{\mathrm{s}}$ are appropriately selected, it is likely that $E_{j} \leq 1, j=1,2, \ldots, n$. If we make evaluation on the $\mathrm{J}_{0}^{\text {th }} \mathrm{DMU}$, which is marked as $\mathrm{DMU}_{0}$, and its input is $\mathrm{X}_{0}$ and its output is $\mathrm{Y}_{0}$, then the fractional programming model of the asset quality of the $\mathrm{J}_{0}^{\text {th }}$ DMU is as below: 


$$
\left\{\begin{array}{c}
\max \frac{U^{T} Y_{0}}{V^{T} X_{0}} \\
\text { s.t. } \quad E_{j}=\frac{U^{T} Y_{j}}{V^{T} X_{j}} \leq 1 \\
\sum_{r=1}^{s} u_{r}=1 \sum_{i=1}^{m} v_{i}=1 \\
u \geq 0, v \geq 0 \\
j=1,2, \cdots n
\end{array}\right.
$$

According to Charness-Cooper conversion and dual programming theory, the fractional programming model can be converted into the linear programming model:

$$
\left\{\begin{array}{l}
\min \theta \\
\text { s.t. } \quad \sum_{j=1}^{n} X_{j} \lambda_{j} \leq \theta X_{0}, \mathrm{j}=1,2, \ldots, \mathrm{n} . \\
\sum_{j=1}^{n} Y_{j} \lambda_{j} \geq Y_{0}, \lambda_{j} \geq 0
\end{array}\right.
$$

When we solve the above linear programming model, we can get the value of the parameter $\lambda \mathrm{j}$ and $\theta$ in the model. The value of $\theta$ represents the asset quality of an enterprise.

When $\theta=1$. It indicates that the asset quality of $\mathrm{DMU}_{0}$ is relatively high. That is to say, among the $\mathrm{n}$ enterprises that are evaluated, it is optimal when the output $\mathrm{Y}_{0}$ is on the basis of the input $\mathrm{X}_{0}$.

When $\theta<1$, it indicates that investment of $\mathrm{DMU}_{0}$ is relatively ineffective, namely, $\mathrm{DMU}_{0}$ can reduce its input to $\theta \mathrm{X}_{0}$ while the original output $\mathrm{Y}_{0}$ remains unchanged. Under the $\mathrm{C}^{2} \mathrm{R}$ Model, if the process of quality generating is not one with effectiveness of scale, then we can further analyze or decide the increase and decrease trend of returns to scale. When and only when:

$\sum_{j=1}^{n} \frac{\lambda_{j}}{\theta}\left[1\right.$, returns to scale increase; when $\sum_{j=1}^{n} \frac{\lambda_{j}}{\theta}, 1$, returns to scale decrease.

\section{Conclusions and disadvantages}

Introduction of DEA Model in analysis of asset quality avoids the difficulty of setting up an analytic function formula and makes it possible to successfully conduct analysis and evaluation of quality and economy. From the micro perspective, information gained from the DEA Method has provided quantified evidence for an enterprise to update its technology, renew its assets and improve its quality management. From the macro perspective, the optimized allocation of resources with the reference data offered from the DEA Method will obtain better social and economic profits.

However, when the traditional DEA Model evaluates the asset quality of an enterprise, it only classifies the evaluation object into the two categories of effectiveness and ineffectiveness, and is unable to further subdivide the difference between the effective DMU $(\theta=1)$. Thus, it is often difficult for the traditional DEA Model to satisfy need of the operation and management of the enterprise. That is to say, the asset quality of those relatively effective enterprises that are evaluated is comparatively high, so there is no way to further distinguish differences of these enterprises in terms of their asset quality. 


\section{References}

Bernstein, David. (1996). Asset Quality and Scale Economies in Banking. Journal of Economics and Business.

Du, Wenxian \& Wu, Linhai. (2009). DEA Analysis of R\&D Investment Relative Efficiency in China. Scientific Management Research, April.

Gan, Shengdao \& Wang, Shengbing. (2000). On Optimization and Evaluation of Quality of Enterprise Assets. Journal of Sichuan University, May.

Harris, M. and Raviv. (1990). Capital Structure and the Informational Role of Debt. Journal of Finance.

Li, Jiaming \& Li, Songmin. (2005). Empirical Research on Asset Quality and Enterprise Performance of Listed Companies in China. Inquiry into Economic Problems, April.

Qian, Aimin \& Zhang, Xinmin. (2009). Asset Quality: Definition and Characteristics. Research on Financial and Economic Issues, August.

Wang, Jianqiang \& Yang, Jianjun. (2010). Evaluation on Enterprise Investment Efficiency Based on DEA Model. Science Research Management, July.

Zhang, Xinmin. (2008). Financial statements analysis. China Renmin University Press, September.

Table 1. Index system of evaluation on asset quality

\begin{tabular}{|c|c|c|c|}
\hline Category & $\begin{array}{c}\text { Serial } \\
\text { number }\end{array}$ & Name of index & Calculation and getting the value \\
\hline \multirow[t]{6}{*}{ Input index } & $\mathrm{X} 1$ & Monetary assets & $\begin{array}{l}\text { Final value of the report }+ \text { transaction financial } \\
\text { assets }+ \text { short-term bond }\end{array}$ \\
\hline & $\mathrm{X} 2$ & Debt assets & $\begin{array}{c}\text { Accounts receivable }+ \text { notes receivable }+ \text { account } \\
\text { prepaid }+ \text { interest receivable }+ \text { other accounts } \\
\text { receivables }\end{array}$ \\
\hline & $\mathrm{X} 3$ & Inventory & Final value of the report \\
\hline & $\mathrm{X} 4$ & $\begin{array}{l}\text { External speculative } \\
\text { assets }\end{array}$ & $\begin{array}{c}\text { Financial assets available for sale }+ \text { financial } \\
\text { assets held to maturity }+ \text { long-term equity } \\
\text { investment }\end{array}$ \\
\hline & $\mathrm{X5}$ & Permanent assets & Final value of the report \\
\hline & $\mathrm{X} 6$ & Intangible assets & Final value of the report \\
\hline \multirow{5}{*}{$\begin{array}{l}\text { Output } \\
\text { value }\end{array}$} & Y1 & Operating income & Final value of the report \\
\hline & $\mathrm{Y} 2$ & Core profit & $\begin{array}{l}\text { Operating income - operating cost - operating } \\
\text { tariff and annex- period expense }\end{array}$ \\
\hline & Y3 & $\begin{array}{c}\text { Net profit after } \\
\text { deducting } \\
\text { extraordinary gains and } \\
\text { losses }\end{array}$ & Disclosure value of the financial report \\
\hline & Y4 & $\begin{array}{c}\text { Cash flow in operation } \\
\text { activities }\end{array}$ & Final value of the report \\
\hline & Y5 & $\begin{array}{l}\text { Net amount of cash } \\
\text { flow }\end{array}$ & Final value of the report \\
\hline
\end{tabular}

